\title{
CONTROLE DO FORNECIMENTO E DA UTILIZAÇÃO DE SUBSTRATOS ENERGÉTICOS NO ENCÉFALO
}

\author{
A. O. SCHELP*, R.C. BURIN"*
}

RESUMO - Correspondendo a apenas $2 \%$ do peso corpóreo, o cérebro apresenta taxa metabólica superior à maioria dos demais orgãos e sistemas. A maior parte do consumo energético encefálico ocorre no transporte iônico para manutenção do potencial de membrana celular. Praticamente desprovido de estoques, os substratos energéticos para o encéfalo são fornecidos necessariamente pela circulação sanguínea.O suprimento desses substratos sofre também a ação seletiva da barreira hemato-encefálica (BHE). O principal substrato, que é a glicose, tem uma demanda de $150 \mathrm{~g} / \mathrm{dia}(0,7 \mathrm{mM} / \mathrm{g} / \mathrm{min})$. A metabolização intracelular parece ser controlada pela fosfofrutoquinase. A manose e os produtos intermediários do metabolismo (frutose 1,6 bifosfato, piruvato, lactato e acetato) podem substituir, em parte, a glicose, quando os níveis sanguíneos desta encontram-se elevados. Quando oxidado, o lactato chega a responder por $21 \%$ do consumo cerebral de $\mathrm{O}_{2}$. Em situações de isquemia e inflamação infecciosa, o tecido cerebral passa de consumidor a produtor de lactato. Os corpos cetônicos também podem reduzir as necessidades cerebrais de glicose desde que oferecidos em quantidades suficientes ao encéfalo. Entretanto, devem ser considerados como um substrato complementar e nunca alternativo da glicose, pois comprometem a produção cerebral de succinil CoA e GTP. Quanto aos demais substratos, embora apresentem condições metabólicas, não existem demonstrações consistentes de que o cérebro produza energia a partir dos ácidos graxos sistêmicos, mesmo em situações de hipoglicemia. De maneira análoga, etanol e glicerol são considerados apenas a nível de experimentaçāo. A utilização dos aminoácidos é dependente da sua captaçāo, limitada tanto pela baixa concentração sanguínea, como pela seletividade da BHE. A maior captaçāo ocorre para os de cadeia ramificada e destes, a valina. A menor captação é a de aminoácidos sintetizados no cérebro (aspartato,gluconato e alanina). Todos podem ser oxidados a $\mathrm{CO}_{2}$ e $\mathrm{H}_{2} \mathrm{O}$. Entretanto, mesmo com o consumo de glicose reduzido a $\mathbf{5 0 \%}$, a contribuição energética dos aminoácidos não ultrapassa $10 \%$. Para manter o suprimento adequado de glicose e oxigênio, o fluxo sanguíneo cerebral é da ordem de $800 \mathrm{ml} / \mathrm{min}$ (15\% do débito cardíaco). $O$ consumo de $\mathrm{O}_{2}$ pelo cérebro é equivalente a $20 \%$ do total consumido pelo corpo. Esses mecanismos, descritos como controladores da utilização de substratos energéticos pelo cérebro, sofrem a influência da idade apenas no periodo perinatal, com a oxidaçāo do lactato na fase pré-latente e dos corpos cetônicos, no início da amamentaçāo.

PALAVRAS- CHAVE: cérebro, substratos energéticos, metabolismo.

\section{Modulation of energy substrate supply and consumption by the brain}

SUMMARY - Altrough accounting for $2 \%$ of body weight, brain has one of the greatest metabolic rates compared with other organs and systems. The energy metabolic consum is expended mainly in the maintenance of ionic gradient, essential to neuronal activity. Brain receives energy substrates from circulation, with interference of blood brain barrier (BBB). Glucose is the main substrate and has a metabolic rate so high as $150 \mathrm{~g} /$ day $(0.7$ $\mathrm{mM} / \mathrm{G} / \mathrm{min}$ ). At cellular level, metabolism of glucose seems to be controlled by phosphofructokynase. If the cellular level were high enough, manose and other products like fructose 1,6 biphosphate, pyruvate, lactate and acetate can be used in the place of glucose. Lactate, when oxyded, consums at least $21 \%$ of the cerebral needs of $\mathrm{O}_{2}$. In ischemia and inflammatory infections, brain tissue produces lactate instead of use it. Ketone bodies

Faculdade de Medicina de Botucatu da Universidade Estadual Paulista (UNESP): *Médico, pósgraduando do curso de Patologia; **Professor Titular Departamento de Clínica Médica, Chefe do Laboratório de Bioquímica Nutricional e Metabólica. Aceite: 15-abril-1995.

Dr. Arthur Oscar Schelp - Departamento de Neurologia e Psiquiatria, Faculdade de Medicina de Botucatu, UNESP - 18618-000 Botucatu SP - Brasil. 
reduce cerebral needs of glucose; in view of the disturbances that occur in cerebral production of succinyl CoA and guanosine 3 phosphate (GTP), they must be considered as complementary substrate but not as an alternative one. Although they can be metabolized, there are no evidences that brain could produce energy from systemic free fatty acids, even when hypoglicemia is present. Ethanol and glycerol are considered only at experimental level. Brain uptake of aminoacids occur better for long chain aminoacids, specially valine. The aminoacids that are synthetised in the brain (aspartate,gluconate and alanine) show the lower absortion rates. All aminoacids should be oxided to $\mathrm{CO}_{2}$ and $\mathrm{H}_{2} \mathrm{O}$. Even when glucose consum is reduced to $30 \%$, aminoacid accounts for only $10 \%$ of the energetic expenditure of the brain. To maintain cerebral glucose and oxygen supply to the brain, blood flow must be at least $800 \mathrm{ml} / \mathrm{min}$. The regulation of supply and consumption of energy substrate by the brain is changed in few situations. Among them, are included the oxidation of lactate immediately before milk diet early in development and utilization of ketone bodies at the beginning of lactation. This review includes a brief discussion about the relevance of glucose as the main energy substrate for cerebral tissue in different ages and ischemia or hypoxia.

KEY WORDS: brain, energy substrate, metabolism.

Praticamente todas as substâncias necessárias ao metabolismo energético cerebral, com exceção do oxigênio, são derivadas direta ou indiretamente da dieta ${ }^{12,3 n}$, sendo que a oferta desses substratos à célula cerebral depende da sua concentraçāo sanguínea, do fluxo sanguíneo cerebral e da seletividade da barreira hêmato-encefálica (BHE). É de consenso, através de demonstrações tanto no homem como no cão, que reduçōes na concentração do oxigênio inspirado não alteram o fluxo vascular cerebral antes da pressão arterial média (pO2) cair abaixo de $50 \mathrm{~mm} / \mathrm{Hg}^{20}$. Estudos com tomografia em campo de emissão de positrons (PET) evidenciaram existir relação estequiométrica entre a oxidaçāo da glicose e o fluxo vascular cerebral ${ }^{21}$. Apesar de haver função de síntese de hormônios e neurotransmissores, ć estimado que a maior parte do consumo cnergético encefálico ocorre em função do transporte iônico ${ }^{35}$, necessário à manutenção e/ou restauração do potencial de membrana, durante os processos de excitaçāo c inibição sinápticos. Usualmente, existe tendência a relacionar hiper e hipometabolismo com excitação e inibição neuronais ${ }^{7}$, pressupondo maior e menor gasto energético, respectivamente. Neste sentido, foi demonstrado que crises epilépticas se acompanham de aumento da atividade córtico-encefálica ${ }^{18}$. No entanto, normalmente, mudanças de vigília para sono profundo, ou mesmo o esforço mental, não alteram significativamente o metabolismo e fluxo vascular ccrebrais ${ }^{21}$. Estes dados sugerem que distúrbios regionais, que não alteram o metabolismo cerebral como um todo, são compensados pela atividade restante ${ }^{35}$, mantendo o conceito de estequiometria. Já os estudos com a 2-deoxiglicose demonstraram, claramente, que tanto os eventos sinápticos excitatórios como os inibitórios requerem energia'. Assim, o hipermetabolismo focal, observado em PET scanners ictais de pacientes epilépticos, representaria atividades excitatórias e inibitórias aumentadas ${ }^{7}$. Por outro lado, os estudos com a $18 \mathrm{~F}$-fluordeoxiglicose, interictais, em situação basal de repouso (steady-state), revelam hipometabolismo, focal e generalizado".

Este estudo pretende rever os processos controladores de substratos energéticos encefálicos que possam influenciar suas situaçōes de hipo e hipermetabolismo.

\section{FORNECIMENTO DE SUBSTRATOS ENERGÉTICOS AO ENCÉFALO}

Diferentemente dos demais orgãos, a perfusão do tecido encefálico, com sangue rico em nutrientes, não significa suprimento adequado, pois a BHE facilita ou retarda seletivamente a passagem de nutrientes da circulação sistêmica para o encéfalo. Dentre os vários processos que norteiam a passagem de substâncias pela BHE, a difusão simples é a mais importante, sua efetividade variando com o grau de lipossolubilidade do soluto e com a habilidade deste em se dissolver na membrana endotelial ${ }^{26}$. A maioria dos compostos hidrofílicos, os quais incluem os principais substratos energéticos, atravessam a BHE mediante carreadores saturáveis, na maioria das vezes estereoespecíficos, seguindo a cinética de Michaelis-Menten. Portanto, a velocidade de transporte depende, não só do tipo e concentração da substância transportada mas, também das constantes Km e V max do carreador $^{30}$ (Fig 1). 


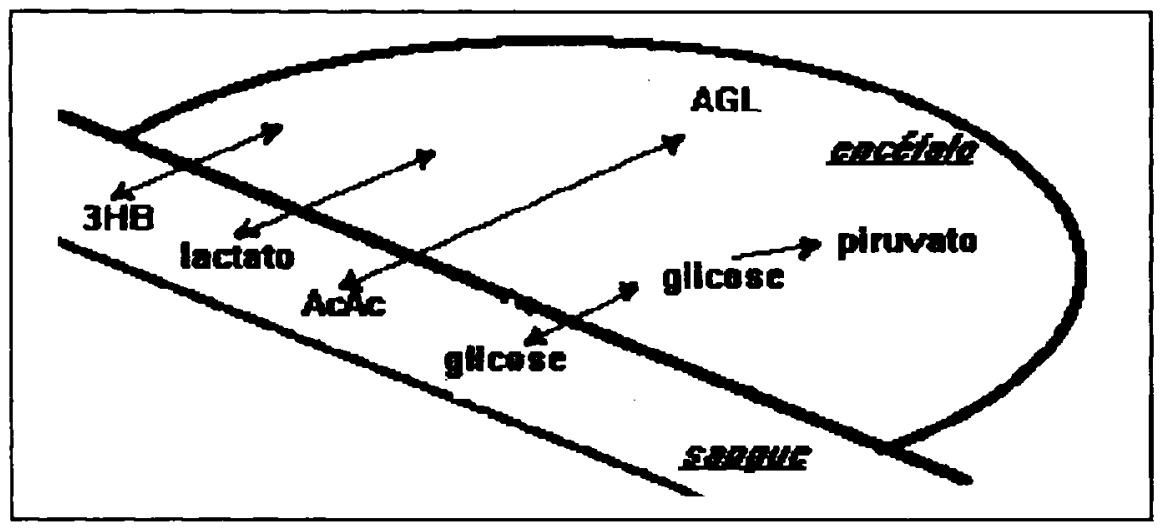

Fig 1. Diagrama simplificado mostrando os principais substratos encefálicos e relação com a barreira hêmato-encefálica. AGL, ácidos graxos livres; AcAc; acetoacetato; $\rightarrow$ direçäo de fluxo do substrato em relação a barreira hêmato-encefálica.

GLICOSE. O consumo cerebral de glicose é calculado em $150 \mathrm{~g} / \mathrm{dia}$, correspondendo a cerca de $2 / 3$ da produção hepática ${ }^{y}$. A metabolização cerebral deste substrato é essencialmente aeróbica, na base de $31 \mathrm{mM}$ de glicose por $156 \mathrm{mM}$ de $\mathrm{O} 2$, com liberação de $156 \mathrm{mM}$ de $\mathrm{CO} 2$ por $\mathrm{mg}$ de tecido por minuto, resultando em quociente respiratório próximo da unidade. Para este consumo de glicose foi verificado que apenas $26 \mathrm{mM} / 100 \mathrm{~g} / \mathrm{min}$ sāo oxidados, sendo que o destino do restante permanece indefinido, especulando-se que seja utilizado na formaçāo de compostos intermediários como o lactato e piruvato, ou na síntese de outras substâncias, como os neurotransmissores ${ }^{\mathrm{t} .1 !}$.

Apesar dos estoques cerebrais de glicose e precursores serem mínimos e aparentemente insuficientes para o atendimento da demanda energética, existem evidências de que o glicogênio encefálico é rapidamente mobilizado para atender a demanda metabólica da glia, em situações agudas em que ocorrem súbitas elevações na demanda metabólica ou em situaçōes de isquemia ou hipóxia ${ }^{31}$. Assim, pode-se identificar duas fases de resposta metabólica, uma fase glicolítica, precoce e rápida de "clearance" do potassio e uma fase mais lenta, associada ao "pool"de ATP oxidativo ${ }^{2 \mathrm{~N}}$. Esta fase, de manutenção das condições basais necessita de suprimento contínuo de sangue, sendo que a glicose ofertada às células cerebrais excede, normalmente, a demanda. A passagem de glicose pela BHE ocorre mediante carreadores, designados como Gluts (glucose transporters), que são proteínas cuja saturação ocorre somente com elevados níveis de glicemia. Os mecanismos que regulam a estreita relação entre BHE e metabolismo da glicose cerebral não estão perfeitamente elucidados ${ }^{13}$. Têm sido apontados fatores como o aumento do leito capilar em resposta às elevaçōes da atividade metabólica cerebral ${ }^{3}$, bem como translocação de proteínas transportadoras do endotélio subcelular, de organclas para sítios ativos da membrana celular ${ }^{17}$.

A captação de glicose pela célula cerebral ocorre por processo independente da insulina, sendo imediatamente fosforilada no carbono 6, formando a glicose-6-fosfato (G-6-P). Estudos in vitro mostraram que a hexoquinase cerebral apresenta $\mathrm{Km}$ baixo, próximo aos valores da Vmax, que é equivalente a 15-30 vezes o influxo cerebral de glicose $(0,7 \mathrm{mM} / \mathrm{g} / \mathrm{min})^{26}$. Portanto, é bastante improvável que a fosforilação seja fator limitante da glicólise cerebral. Uma vez fosforilada, a glicose é metabolizada preferencialmente (cerca de 90\%) a priruvato $\mathrm{e}$, deste, a $\mathrm{CO}_{2} \mathrm{e}_{2} \mathrm{O}$. Há evidências de que a formação de glicogênio pela célula nervosa seja negligivel e que apenas $1 \%$ da glicose seria metabolizada no shunt das pentoses. A fosfofrutoquinase é considerada a principal enzima reguladora da glicólise cerebral. Em tecidos musculares, hepático e renal, esta enzima é ativada pelo AMP, Pi e frutose 1,2 bifosfato e inibida pelos níveis de ATP e citrato. A metabolizaçāo anaeróbica da glicose a lactato produz, no máximo, $47-52 \mathrm{Cal} / \mathrm{mol}$, enquanto sua metabolização oxidativa, a $\mathrm{CO}_{2}$ e $\mathrm{H}_{2} \mathrm{O}$, produz aproximadamente $690 \mathrm{Cal} / \mathrm{mol}$ (equivalente a $38 \mathrm{ATP}$ ). A eficiência do processo glicolítico, na geração de energia, é cerca de $40 \%$.

Dentre os demais carboidratos simples, a manose parece ser a unica a ser utilizada direta e rapidamente pelo cérebro, em substituição à glicose, sem perdas na função celular. Entretanto, os níveis desta substância na circulação são înfimos em condições fisiológicas. Situação semelhante ocorre com substâncias formadas no 
metabolismo intermediário como: frutose 1,6 bifosfato, piruvato, lactato acetato, acetoacetato e betahidroxibutirato, os quais apresentam efetividade dependendo dos seus niveis sanguíneos ${ }^{1}$.

LACTATO. Os ácidos monocarboxílicos (ácido lático, pirúvico, acético, propiônico e burítico) usufruem de um mesmo sistema de transporte através da BHE, mediado por carreador. Isto implica em inibição competitiva entre estas substâncias ${ }^{38}$. No caso do lactato, o sistema transportador é estereoespecífico para o isômero $\mathrm{L}$ e é saturado com níveis 3 a 4 vezes superiores aos valores normais. Entretanto, existem descrições de outro sistema de difusão simples, não saturável, que seria acionado quando da inibição por saturação do sistema anterior ${ }^{3}$.

A utilização de lactato pelos neurônios cresce com a queda da glicemia, sua captação não parecendo ser limitante ao nível da desidrogenase láctica. Quando oxidado completamente pelo cérebro, o lactato pode contribuir com até $21 \%$ do total de $\mathrm{O}_{2}$ consumido pelo encéfalo. Estudos experimentais em cães mostraram que esta taxa pode se elevar até $50 \%$ quando o lactato arterial atinge $3 \mathrm{mM} / /^{15}$. Assim, o lactato pode se constituir em combustível energético substituto da glicose, com grande importância nos estados hipoglicêmicos ${ }^{2}$ (i.e. recém natos) e, talvez, também nos hiper/normoglicêmicos, como no exercício físico intenso ${ }^{19}$. Entretanto, em condiçães de isquemia ou hipóxia e nas atividades inflamatórias agudas e graves (i.e. meningites bacterianas e tuberculosas), o encéfalo passa de consumidor a produtor de lactato"2 (Fig 2).

ÁCIDOS GRAXOS. Com o aumento da sua cadeia carbônica os ácidos graxos tornam-se mais lipofílicos e, consequentemente, de maior mobilidade na $\mathrm{BHE}^{30}$. Os ácidos graxos livres elevam-se no sangue tanto em situações fisiológicas (neonato, exercício físico), como nas patológicas tais como no jejum crônico, hipóxia, hipoglicemia, eletrochoque e convulsões induzidas por drogas ${ }^{38}$.

A oxidação dos ácidos graxos de cadeia longa é acelerada pelo acréscimo de carnitina ${ }^{16}$, tripeptídeo de origem renal, necessário para o transporte de ácido graxo através da membrana mitocondrial. Entretanto, sabese que a captação cerebral de carnitina é fortemente inibida pelo GABA ${ }^{16}$. Portanto apesar de ter como fazê-lo, não há demonstraçōes consistentes de que os ácidos graxos livres ( $A G L$ ) contribuam efetivamente no metabolismo energético cerebral. Apesar de alguns autores considerarem que tal situação persista mesmo em situaçōes de menor consumo de glicose ${ }^{\text {s, }}$, existem estudos que demonstram que, a partir do momento em que o estado energético encefálico entra em falência, ocorre aumento significativo dos níveis de AGL, com queda nos níveis de fosfolipídeos deacetilados pela ação de fosfolipases ${ }^{36}$, acúmulo de ácido esteárico e ácido aracdônico e concomitante elevação do triaciglicerolaracnoidato, como consequência da reacetilaçāo do ácido aracdônico ${ }^{\text {kh }}$. A degradaçāo e ressíntese de fosfolipídeos de membrana celular, pode desempenhar papel importante na

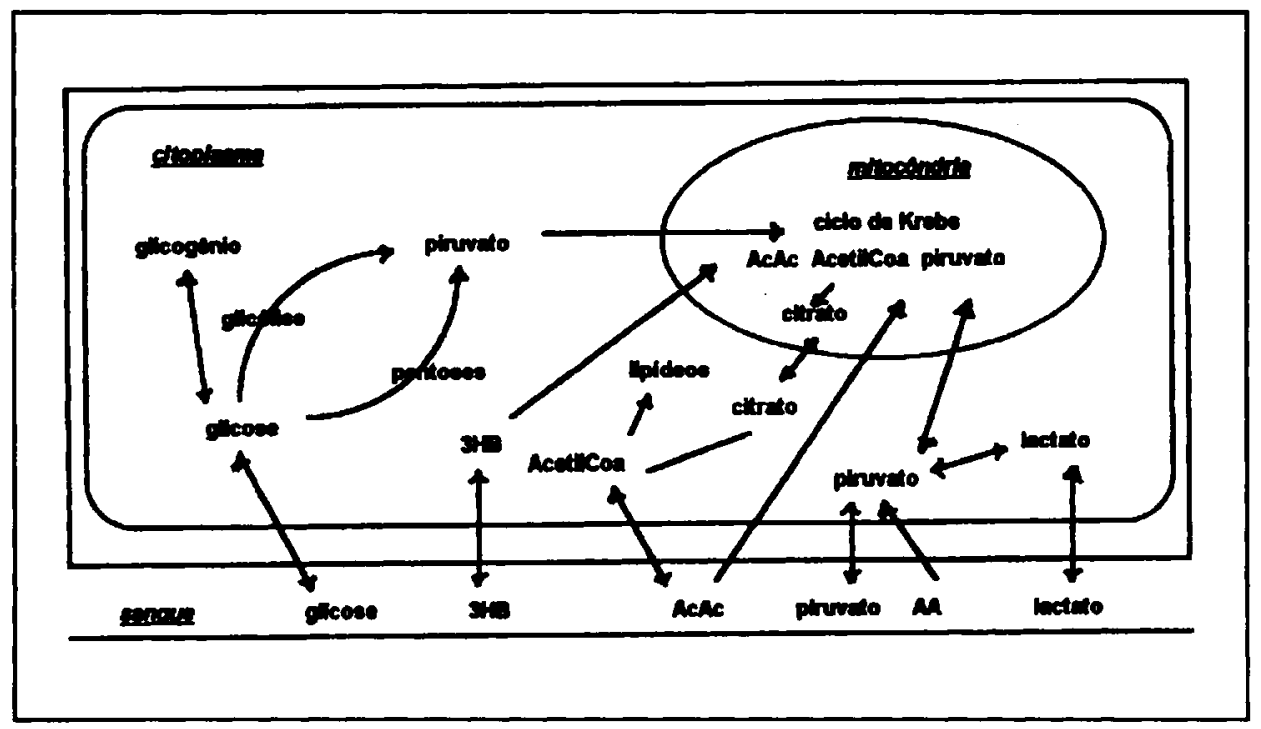

Fig 2. Representação gráfica das principais interconversöes metabólicas dos macronutrientes encefálicoss. $3 H B, 3$ hidroxibutirato; AcAc, acetoacetato; AA, aminoácido. 
modulação dos níveis do ácido aracdônico livre ${ }^{34}$. No entanto este sistema de oxidação e redução ocorre às expensas de AGL, produtos da disrupção de membranas celulares, com modificações na função de receptores de membrana e na transmissão sináptica ${ }^{34}$. $\mathrm{O}$ estudo de Yoshida e col ${ }^{38}$, demonstrou que o acúmulo de AGL ocorre como consequência da ausência de fosforilação oxidativa, ativando enzimas deacetilizadoras, que perpetuam o processo, e da acidose decorrente do acúmulo de ácido lático, acrescido da formação de radicais livres, produtos da metabolização do ácido aracdônico, como de processos de peroxidação, que ocorrem na reoxigenação ${ }^{37}$.

CORPOS CETÔNICOS. As informaçōes existentes sugerem que o transporte dos corpos cetônicos (ácidos acetoacético e beta-hidroxibutírico), através da $\mathrm{BHE}$, seja feito por cameadores estereoespecíficos e saturáveis. Competem para 0 mesmo sistema transportador dos corpos cetônicos, os ácidos láctico, pirúvico, propiônico e butírico ${ }^{14}$. Transposta a BHE, o cérebro tem condições enzimáticas para metabolizar os corpos cetônicos. Basicamente, para que haja formação da AcCoa a partir do acetoacetato, há necessidade das enzimas 3-cetoácido Coa transferase e acetoacetil Coa tiolase. A utilização do D-beta-hidroxibutirato requer a enzima D-beta-hidroxibutirato desidrogenase, na formação do acetoacetato ${ }^{27}$.

Embora estudos demonstrem a importância dos corpos cetônicos como substrato energético cerebral, altemativo à glicose, é importante salientar que, nestas condições, o consumo cerebral de glicose pode se encontrar reduzido, mas nunca ausente. Não há de evidências de que os corpos cetônicos possam substituir totalmente a glicose; pelo contrário, existem dados mostrando detereoração rápida das funçōes cerebrais quando da substituição da glicose por D-beta-hidroxiburitato na perfusão de cérebro isolado de rato ${ }^{14}$. A impossibilidade dos corpos cetônicos, em substituir a glicose no metabolismo energético cerebral, pode ser justificada pela diferenciaçāo das vias metabolicas. O D-beta-hidroxibutirato precisa ser convertido inicialmente a acetoacetato, o qual é metabolizado mediante o deslocamento do radical succinil da SucCoA para oxigenar a AcetoAcCoA. Parece haver uma exceção a esta assertiva, nos lactentes, em que o acetoacetato mostra ser um precursor preferencial na síntese de ácidos graxos e colesterol, presumivelmente porque pode ser utilizado diretamente no citosol neste processo. Em condiçoóes normais, a glicose supriria somente $23 \%$ dos carbonos de colesterol recém sintetizado. Este nível de contribuição não se altera quando existe suplementação adicional na dieta láctea, de carboidratos'.

Em condições normais, a hidrólise da SucCoA está acoplada à produção de GTP (guanosina trifosfato), substância participante direta de funções cerebrais importantes, como síntese proteica e neoglicogênese ou, indiretamente, como precursora da cGMP (guanosina monofosfato cíclica), fundamental na mediação sináptica colinérgica Existem experimentos mostrando maior utilização de acetoacetato por $\mathrm{mg}$ de tecido cerebral, quando incubados em presença de glicose. Isto se deve, provavelmente, a maior oferta de SucCoA, pois sabe-se que as duas moléculas de AcCoA, originárias da molécula de glicose, formam duas moléculas de SucCoA no ciclo de Krebs. A oxidação do acetoacetato, via ciclo de Krebs, também origina duas moléculas de SucCoA sendo, entretanto, uma delas consumida no processo de formação de AcCoA. Assim, a oxidaçào dos corpos cetônicos produz metade da SucCoA gerada pela oxidação da glicose. É possível, portanto, que o uso exclusivo dos corpos cetônicos resulte em depleçāo do conteúdo cerebral de SucCoA e, consequentemente, de GTP, com sérias repercussões anatômicas e funcionais ${ }^{33}$. Em função disto, os corpos cetônicos devem ser considerados apenas como substratos cerebrais suplementares, nāo alternativos à glicose ${ }^{14}$ (Fig 2).

O mecanismo pelo qual a oxidação dos corpos cetônicos inibe a utilizaçăo de glicose cerebral ainda permanece obscuro. Presume-se que seja de modo semelhante ao que ocorre no músculo, ou seja, via elevação da AcCoA e citrato, e consequente inibição da piruvato desidrogenase e fosfofrutoquinase, respectivamente ${ }^{23}$.

ETANOL E GLICEROL. Acredita-se que as enzimas participantes do metabolismo do etanol e do glicerol existam no cérebro, mas em quantidades insuficientes, embora as alteraçōes eletrencefalográficas decorrentes do estado de hipoglicemia (induzida por insulina), possam ser revertidas pela administração de glicerol. Entretanto, para tal, a dose de glicerol administrada foi dez vezes maior que a taxa sérica normal, possível apenas com administração intracarotídea ${ }^{30}$. De modo análogo, foram necessários $25 \mathrm{mM}$ de glicerol para produzir o $\mathrm{CO}_{2}$ equivalente à metabolizaçāo de $2 \mathrm{mM}$ de glicose. Portanto, embora o cérebro tenha condiçōes de metabolizar o glicerol com finalidades energéticas, sua utilização ocone de modo lento e inefetivo, devendo ser considerada apenas em condições de experimentação.

AMINOÁCIDOS. O cérebro tem condições de oxidar os aminoácidos a $\mathrm{CO}_{2}$ e $\mathrm{H}_{2} \mathrm{O}$, desde que oferecidos às suas células. Entretanto, a captação cerebral de aminoácidos é limitada, tanto pela baixa concentraçāo deles no sangue arterial, como pela seletividade da BHE. Existem sistemas específicos para transporte dos aminoácidos 
neutros, ácidos e básicos, sendo a afinidade dos aminoácidos para estes sistemas de transporte baseada, aparentemente, na carga molecular de sua cadeia lateral. Assim, o carreador ácido requer a presença de uma carga negativa, o carreador básico de uma carga positiva e o carreador neutro, de uma carga na cadeia lateral do aminoácido ${ }^{24}$.

Outro aspecto importante é que os aminoácidos circulam no plasma em concentrações próximas ao $\mathrm{Km}$ do sistema transportador na BHE, de modo que a competição entre eles para os sítios de transporte é que regula a entrada deles na circulação encefálica ${ }^{26}$. Como exemplo, tem-se o triptofano, cujo transporte na BHE depende da menor disponibilidade dos demais aminoácidos neutros, cujos representantes quantitativamente mais importantes são os aminoácidos de cadeia ramificada ${ }^{12}$. Os aminoácidos essenciais ao cérebro (Phe, Tyr, Leu, Val, Met e Tre) são transportados de modo mais efetivo que os sintetizados pelo órgāo (Asp. Glu e Ala). Todos esses aminoácidos podem ser oxidados a $\mathrm{CO}_{2}$ e $\mathrm{H}_{2} \mathrm{O}^{10}$. A velocidade de oxidação dos aminoácidos de cadeia ramificada (Leu, lleu e Val), por mg de tecido cerebral, foi comparável à verificada no rim e diafragma. No caso da leucina, a oxidação abrange $90 \%$ da quantidade captada, sendo os $10 \%$ restantes utilizados na síntese peptídica.

Medidas arteriovenosas no cérebro de humanos, no período pós-prandial, mostraram captação de 15 dos 16 aminoácidos testados, à exceção da taurina. A captação dos aminoácidos de cadeia ramificada foi maior que a dos demais e, dentre esses, a de valina foi a mais elevada. Entretanto, a somatória dos aminoácidos captados atingiu apenas $125 \mathrm{mM} / \mathrm{l}$, o que, comparado aos $560 \mathrm{Mm} / \mathrm{L}$ da glicose, oferece uma estimativa da pequena contribuição energética, principalmente ao se considerar que nem todos os aminoácidos são oxidados. Foi demonstrado que, mesmo nos pacientes em jejum crônico, com redução de $50 \%$ no consumo de glicose cerebral, a contribuição energética dos compostos alfa-amínicos nāo ultrapassou 10\%. Assim, embora o cérebro tenha capacidade plena para oxidação dos aminoácidos, a contribuiçāo deles para o metabolismo energético cerebral é relativamente pequena (Fig 2).

INFLUÊNCIA DA IDADE. O cérebro que contribui corn cêrca da metade do gasto energético total da criança, reduz sua participação em relação ao peso corporal durante o crescimento e desenvolvimento, de modo que no adulto responde por sómente $20 \%$ do gasto energético global ${ }^{6}$. A velocidade do fluxo sanguíneo, nas diferentes estruturas cerebrais, atinge níveis máximos em tempos diferentes, dependendo da velocidade de maturação da àrea irrigada. Na substância branca, os picos coincidem, grosseiramente, com os períodos de mielinizaçāo rápida. Após alcançar estes picos, o fluxo sanguíneo e, provavelmente, a velocidade metabólica cerebral, declinam até os níveis característicos da idade adulta ${ }^{30}$. $\mathrm{Na}$ ausência de doença, o fluxo sanguíneo e o consumo de $\mathrm{O}_{2}$ permanecem inalterados, da maturidade à velhice ${ }^{33}$.

Ao se avaliar os efeitos da idade sobre o metabolismo cerebral, é fundamental considerar os experimentos mostrando que o sistema mitocondrial, produtor de energia para o cérebro de ratos, intactos e bem irrigados, não sofre efeitos do envelhecimento per se. No entanto, súbitas elevaçōes na demanda energética cerebral, em pacientes jovens, levam a aumento na utilização de $\mathrm{O}_{2}$ e concomitante elevação da atividade metabólica oxidaçãodependente. No paciente idoso, ao contrário, haverá limitação na utilização de maior oferta de $\mathrm{O}_{2}$, o que podese inferir pela resposta vascular semelhante, com menor utilização de $\mathrm{O}_{2}{ }^{13}$. Outros estudos complementam estas afirmações, demonstrando a estequiometria entre fluxo vascular cerebral, fração de extração de $\mathrm{O}_{2}$ e fração de $\mathrm{O}_{2}$ utilizado em dado momento, indicando assim que o suprimento de $\mathrm{O}_{2}$ é ajustado regionalmente, de acordo com a demanda metabólica ${ }^{21}$.

Os principais mecanismos de adaptaçāo energética cerebral parecem ocorrer no período peri-natal. No final da gravidez, o cérebro do feto nutre-se de glicose de origem materna. Nesta fase, a utilizaçāo de glicose ocorre de modo inadequado, em função da pequena oxigenação do sangue no feto, acarretando grande produção de lactato ${ }^{2}$. Como consequência deste quadro metabólico, o recém nascido apresenta, nas primeiras horas, hipoglicemia instalada temporariamente, em função da glicogenólise ineficiente e da imaturidade das enzimas participantes da neoglicogênese ${ }^{4}$. Nesta fase, o substrato energético disponível em maior quantidade é o lactato's., havendo evidências experimentais de que a sua oxidação, com produção de energia, constitua mecanismo importante na homeostase energética cerebral durante as duas primeiras horas de vida?

Quando disponíveis, os corpos cetônicos constituem combustível acessivel, suprindo equivalentes acetil, dirctamente da lipogênese citoplasmática ${ }^{5.24}$. Se considerarmos que o cérebro é capaz de produzir, em quaisquer circunstâncias, seus principais lípides, como o colesterol e ácidos graxos, como o palmitato, devemos considerar os substratos fornecedores de unidades de carbono, como unidades independentes básicas, pois o mesmo substrato, provavelmente, supre a energia necessária para que os referidos eventos, se completem ${ }^{29}$. Consequentemente, o 
cérebro em desenvolvimento tem de mostrar enorme flexibilidade no aproveitamento destes substratos, para atingir tanto as necessidades de energia, como de substratos precursores, essenciais na miríade de processos biossintéticos que acontecem no período de maturação. Finalmente, cabe ressaltar que a glicose desempenha papel essencial como substrato completo, nas várias etapas do processo.

\section{REFERÊNCIAS}

1. Ackermann RF, Finch DM, Babb TL, Engel JJr. Hippocampal recurrent inhibition: decreased pyramidal cell firing with increased metabolism in the pyramidal cell layer demonstrated by the 2-deoxyglucose autoradiographic technique. Soc Neurosci Abstr 1981, 7:457.

2. Arizmendi $\mathrm{C}$, and Medina JM. Lactate as an oxidizable substrate for rat brain in vitro during the perinatal period. Biol Neonate $1983,44: 36-41$.

3. Cremer JE, Cunningham VJ. and Seville MP. Relatioships between extraction and metabolism of glucose, blood flow, and tissue blood volume regions of rat brain. J Cer Blood Flow Metab 1983, 3:291-302.

4. Cuezva JM., Moreno FS., Medina JM., Mayor F. Prematurity in the rat: fuels and gluconeogenic cnzymes. Biol Neonate 1980, 37: 88-95.

5. Edmond J. Energy metabolism in developing brain cells. Can J Physiol Pharmacol 1992, 70:SI18-S129.

6. Elia M. Organ and tissue contribution to metabolic rate. In Kinney JM, Tucker HE (eds). Energy metabolism: tissue determinants and cellular corollaries, Part I, New York, Raven Press, 1992, p.61-80.

7. Engel J Jr. Kuhl. DE, Phelps ME, Rausch. R, Nuwer M. Local cerebral metabolism during partial seizures. Neurology 1983,33:400-413.

8. Engel J Jr, Kuhl DE, Phelps ME and Mazziotta JC. Interictal cerebral glucose metabolism in partial epilepsy and its relation to EEG changes. Ann Ncurol 1982, 12: 507-517..

9. Felig P, Marliss EB. Cahill GF Jr. Metabolic response to human growth hormone during prolonged starvation. J Clin Invest 1971, 50:411-420.

10. Gardiner RM. The effect of feeding on cerebral blood flow and oxygen consumption in the new-born calf [Proceedings]. J Physiol (London) 1979,296:54.

11. Gibson GE, Jope R, Blass J. Decreased synthesis of acetylcholine accompanyng impaired oxidation of pyruvic acid in rat brain minces. Biochem J, 1975, 148:17-23.

12. Growdom JH, Wurtman FJ. Neurotransmitter synthesis: control by availability of dietary precursors. In Carenza L et als (eds) Clinical psychoneuroendocrinology in reprodution. London: Academic Press, 1979, p $127-138$

13. Harik SI. Changes in the glucose transporter of brain capillaries. Can J Physiol Pharmacol 1992, 70: S113S117.

14. Hawkins RA, Bibuyck JF. Ketone bodies are selectively used by individual brain regions. Science 1979 , 205:325-327.

15. Hellmann J, Vannuci RC, Nardis EE. Blood-brain permeability to lactic acid in the new-born dog: lactate as a cerebral metabolic fuel. Ped Res 1982, 16:40-44.

16. Huth PJ, Schmidt M.J, Hall PV, Fariello RG, Shug AL. The uptake of carnitine by slices of rat cerebral cortex. J Neurochem 1981, 36:715-723.

17. Kasanicki MA, Pilch PF. Regulation of glucose transporter function. Diabetes Care 1990, 13:219-227.

18. Kato M, Malamut BL, Caveness WF et al. Local cerebral glucose utilization in newborn and pubescent monkeys during focal motor seizures. Ann Neurol 1980, 7:204-212.

19. Larrabee MG.Lactate uptake and release in the presence of glucose by sympathetic ganglia of chicken embryos and by neuronal cultures prepared from these ganglia J Neurochem 1983, 40:1237-1250.

20. Lassen NA.Cerebral bood flow and oxygen consumption in man. Physiol Rev 1959, 39:183-238.

21. Lebrun-Grandié P, Baron JL, Soussaline F et al. Coupling betwen regional blood flow and oxygen utilization in the normal human brain. Arch Neurol 1983, 40:230-236.

22. Ljunggren B, Ratcheson RA., Siesjö BK.Cerebral metabolic state following complete compression ischemia. Brain Res 1979, 73:291-307.

23. Newsholme EA, Leech AR(eds). Biochemistry for the medical sciences. London: John Wiley \& Sons, 1983, p336-356.

24. Oldendorf WH, Crane PD, Vraun LP. Wade LA, Diamond JM. Blood-brain barrier transport of basic amino acids is selectively inhibited at low pH. J. Neurochem 1983, 40:797-800.

25. Owen ED, Reichard GA Jr.Human forearm metabolism during progressive staryation. J Clin Invest 1971, 50:1536-1543.

26. Pardridge WM, Oldendorf WH.Transport of metabolic substrates through the blood- brain barrier. J. Neurochem 1977, 28:3-12. 
27. Robinson AM, Williamson DH. Physiological roles of ketone bodies as substrates and signals in mammalian tissues. Physiol Rev 1980, 60:143-187.

28. Rosenthal M, Sick TJ. Glycolytic and oxidative metabolic contributions to potassium ion transport in rat cerebral cortex. Can J Physiol Pharmacol $1992,70:$ 165-S169.

29. Shambaugh GE III, Angulo MC, Koehler. RR. Fetal fuels: VII Ketone bodies inhibit synthesis of purines in fetal rat brain. Am J Physiol 1984, 247:E111-E117.

30. Sokoloff L, Reivich M, Kennedy C, et al. The [14C] deoxyglucose method for the measurement of local cerebral glucose utilization: theory,procedure and normal values in the conscious and anesthetized albino rat. J. Neurochem 1977, 28:887-916.

31. Swanson RA. Physiologic coupling of glial glycogen metabolism to neuronal activity in brain. Can J Physiol Pharmacol 1992, 70:S138-S 144.

32. Sylvia AL, Rosenthal M. Effects of age on brain oxidative metabolism in vivo. Brain Res 1979,165:235248.

33. Takei H, Fredericks WR, London, ED, Rapoport SI. Cerebral blood flow and oxidative metabolism in conscious fischer.-344 rats of different ages. J Neurochem 1983, 40: 801-805.

34. Wieloch T, Harris RJ, Symon L, Siesjö BK. Influence of severe hypoglicemia in brain extracellular calcium and potassium activities, energy, and phospholipid metabolism. J Neurochem 1984, 43:160-68.

35. Yarowsky PJ, Ingvar DH. Neuronal activity and energy metabolism . Fed Proc (FASEB) 1981, 40:23532362.

36. Yoshida S, Ikeda M, Busto R et al. Cerebral phosphoinositide, triacylglycerol, and energy metabolism in reversible ischemia: origin and fate of free fatty acids. J Neurochem $1986,47: 744-757$.

37. Yoshida $S$, Inoh $S$, Asano $T$ et al. Effect of transient ischemia on free fatty acids and phospholipids in the gerbil brain. J Neurosurg 1980, 53:323-331.

38. Yoshida S, Harik SI, Busto R et al. Free fatty acids and energy metabolites in ischemic cerebral cortex with noradrenaline depletion. J Neurochem 1984, 42:711-717. 